\title{
Skin Eruptions in Acute Hemorrhagic Edema of Young Children: Systematic Review of the Literature
}

\author{
Gabriel Bronz $^{\mathrm{a}, \mathrm{b}}$ Pietro O. Rinoldi ${ }^{\mathrm{a}}$ Camilla Lavagno $^{\mathrm{a}}$ Mario G. Bianchetti ${ }^{\mathrm{a}, \mathrm{b}}$ \\ Sebastiano A.G. Lavac ${ }^{c}$ Federica Vanoni ${ }^{a}$ Gregorio P. Milani ${ }^{d, e}$ Isabella Terrani ${ }^{f}$ \\ Alessandra Ferrarini ${ }^{9}$ \\ aPediatric Institute of Southern Switzerland, Ospedale San Giovanni, Bellinzona, Switzerland; ${ }^{b}$ Family Medicine \\ Institute, Faculty of Biomedical Sciences, Università della Svizzera Italiana, Lugano, Switzerland; 'Pediatric \\ Cardiology Unit, Department of Pediatrics, Centre Hospitalier Universitaire Vaudois and University of Lausanne, \\ Lausanne, Switzerland; 'Pediatric Unit, Fondazione IRCCS Ca' Granda Ospedale Maggiore Policlinico, Milan, Italy; \\ eDepartment of Clinical Sciences and Community Health, Università degli Studi di Milano, Milan, Italy; ${ }^{\mathrm{f} D e p a r t m e n t}$ \\ of Dermatology, Ente Ospedaliero Cantonale, Ospedale Regionale di Lugano, Lugano, Switzerland; ${ }^{9}$ Service of \\ Medical Genetics, Ospedale Italiano di Lugano, Lugano, Switzerland
}

\section{Keywords}

Acute hemorrhagic edema - Cockade purpura with edema · Finkelstein-Seidlmayer disease · Targetoid · Skin eruption

\footnotetext{
Abstract

Background: Acute hemorrhagic edema is a skin-limited small-vessel leukocytoclastic vasculitis, which affects infants 4 weeks to 2 years of age and remits within 3 weeks. The diagnosis is made clinically in not-ill appearing children with acute onset of raised annular or nummular eruptions and edema. In this vasculitis, type, distribution, and evolution of the rash have never been systemically investigated. To address this issue, we employed the data contained in the Acute Hemorrhagic Edema Bibliographic Database, which incorporates all reports on acute hemorrhagic edema. Summary: Key features of rash were documented in 383 children. Annular eruptions in a strict sense, usually targetoid, were reported in 375 (98\%) cases (many children also presented
}

polycyclic or arciform eruptions). Nummular eruptions were also very common ( $n=358 ; 93 \%)$. Purpuric eruptions and ecchymoses were reported in the vast majority of cases. Macules and wheals were described in a minority of cases. Edema, detected in all cases, was mostly painful, indurated and nonpitting. The following regions were affected, in decreasing order, by annular or nummular eruptions: legs, feet, face, arms, ears, trunk, and genitals. With the exception of feet, which were very often affected, the same distribution was reported for edema. The initial eruption was often a wheal or a macule that evolved into a nummular or an annular eruption. Nummular eruptions successively evolved into annular ones. Key Message: This study carefully characterizes type, distribution, and evolution of skin eruption in acute hemorrhagic edema. The data help physicians to rapidly and noninvasively make the clinical diagnosis of this vasculitis.

(C) 2021 The Author(s)

Published by S. Karger AG, Basel karger@karger.com www.karger.com/drm

Karger $\stackrel{\text { ' }}{5}$

BOPEN ACCESS
(C) 2021 The Author(s)

Published by S. Karger AG, Basel

This is an Open Access article licensed under the Creative Common Attribution-NonCommercial-4.0 International License (CC BY-NC) (http://www.karger.com/Services/OpenAccessLicense), applicable to the online version of the article only. Usage and distribution for commercial purposes requires written permission.
Correspondence to:

Gabriel Bronz, gabriel.bronz@ hotmail.com 


\section{Introduction}

Acute hemorrhagic edema of young children, also termed cockade purpura with edema or FinkelsteinSeidlmayer disease, is a skin-limited small-vessel leukocytoclastic vasculitis, which characteristically occurs after a simple, mostly viral, febrile illness [1-4]. It affects infants 4 weeks to 2 years of age and spontaneously remits within 3 weeks with little propensity toward relapses [2-5].

Although vascular immunoglobulin A deposits are not detected in the majority of cases [6], hemorrhagic edema is often deemed to be the infantile variant of immunoglobulin A vasculitis [1-5]. The latter condition presents with a palpable rash mainly affecting the lower extremities and the buttocks [3,4]. Available narrative reviews on hemorrhagic edema state that affected children develop, over $48 \mathrm{~h}$ or less, extensive and symmetrically distributed annular or nummular eruptions (Fig. 1) and edema [2-4]. However, type, distribution, and evolution of the rash over the disease course have never been systematically investigated. To address this issue, we employed the data contained in the Acute Hemorrhagic Edema BIbliographic Database (AHEBID).

\section{Methods}

AHEBID [5-7] progressively integrates all the original articles on acute hemorrhagic edema of young children published after the initial communication in 1913. For this purpose, the bibliography search engines Excerpta Medica, the National Library of Medicine databases, and Google scholar are screened every second month by two of us for "acute hemorrhagic edema," "cockade purpura and edema," and "infantile Henoch-Schönlein purpura" without any language restriction. AHEBID also includes the medical literature on this condition collected by some of us in the early eighties of the last century.

The first systematic literature search was made in January 2019. As of December 31, 2020, the database incorporated 301 original reports (letters, case reports, or full-length articles) published since 1970, which addressed 488 individually documented cases (Fig. 2).

AHEBID [7] is available on request (email: finkelstein-seidlmayer@usi.ch).Furthermore, the raw data extracted for the current analysis may be found on the data repository Zenodo as "Skin eruptions in acute hemorrhagic edema of young children: systematic review of the literature." In all cases, the diagnosis of hemorrhagic edema made in the original reports was reviewed using three classic predefined criteria: raised annular or nummular eruptions and skin edema in a not-ill-appearing child [2-4]. The clinical diagnosis was supported by a biopsy disclosing a nongranulomatous neutrophil infiltration into small-vessel walls with karyorrhexis in 241 cases.

For the present analysis, we included exclusively cases with documented type, distribution, or evolution of skin eruptions. Since numerous and sometimes confusing descriptive terms are used to denote skin eruptions, we developed the glossary reported in Table 1 [8] to define annular or nummular eruptions, edema, petechiae, purpuric eruptions, ecchymoses, macules, simple or papular wheals, and scratch marks. The distinctive signs of inflammatory skin edema, including tenderness (or pain), induration, and absent indentation after pressure were specifically addressed.

A predesigned form was employed to record information about demographics of cases, and type, distribution, or evolution of eruptions. Two authors independently extracted the data in a nonblinded fashion. Uncertainties were resolved through team discussions and consensus.
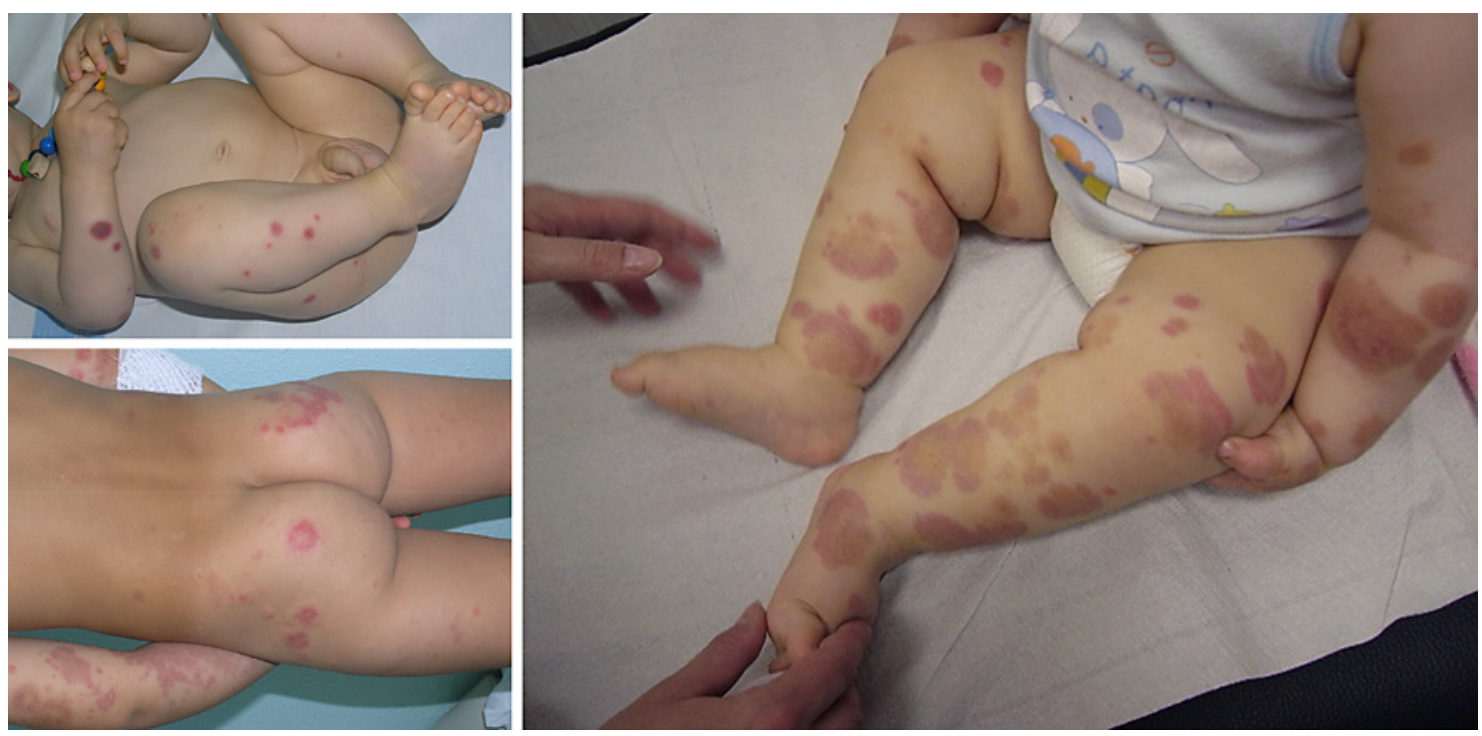

Fig. 1. Nummular and annular skin eruptions in three boys affected by acute hemorrhagic edema of young children. 
Categorical variables are presented as frequency, continuous variables as median and interquartile range. For statistics, the twotailed $\chi^{2}$ test and the Mann-Whitney-Wilcoxon test were used [9]. $p$ values $<0.05$ were considered significant.

\section{Results}

\section{Type and Regional Distribution of Rash}

The skin eruptions were poorly documented in 105 (22\%) cases, 74 boys and 31 girls, 12 (9-20) months of age. The key features of the rash were accurately documented in the remaining 383 (78\%) cases ( 261 boys and 122 girls, 11 [8-18] months of age), mostly $(n=321)$ with the support of photographs. Patients without and with accurately documented skin eruptions did not significantly differ with respect to sex and age.

The skin rash was bilateral and symmetrically distributed in 380 and unilateral in the remaining 3 cases. The skin eruptions reported in the 383 cases appear in Table 2. Annular or nummular eruptions and edema, two inclusion criteria, were reported in all cases. Annular eruptions in a strict sense, usually targetoid, were reported in $98 \%$ of cases and were very often associated with polycyclic (slightly less than every second case) or arciform (approximately every fourth case) eruptions. Nummular eruptions were also reported in more than $90 \%$ of cases. Tenderness or pain $(n=103)$, induration $(n=22)$, and absent indentation after pressure $(n=32)$ characterized skin edema. Purpuric eruptions and ecchymoses (and, occasionally, also petechiae) were reported in the vast majority of cases. Macules and simple or papular wheals were described in a minority of cases. Scratch marks were rarely observed.

The distribution of annular or nummular eruptions, edema, and macules is presented in Table 3. The relative distribution of annular and nummular eruptions was very similar. The following body regions were affected, in decreasing order of frequency, by the two mentioned eruptions: legs and feet, arms and hands, face and ears, trunk, and genitals.

With the exception of feet, which were affected in about three-quarter of cases, the same distribution was reported for edema.

\section{Evolution of Eruptions over the Disease Course}

No detailed information about the evolution of round skin eruptions was provided for 407 cases: 280 boys and 127 girls 11 (9-17) months of age. These data were extracted for the remaining 81 cases: 55 boys and 26 girls 11 (9-17) months of age. Patients without and with docu-

Skin Eruptions in Acute Hemorrhagic

Edema

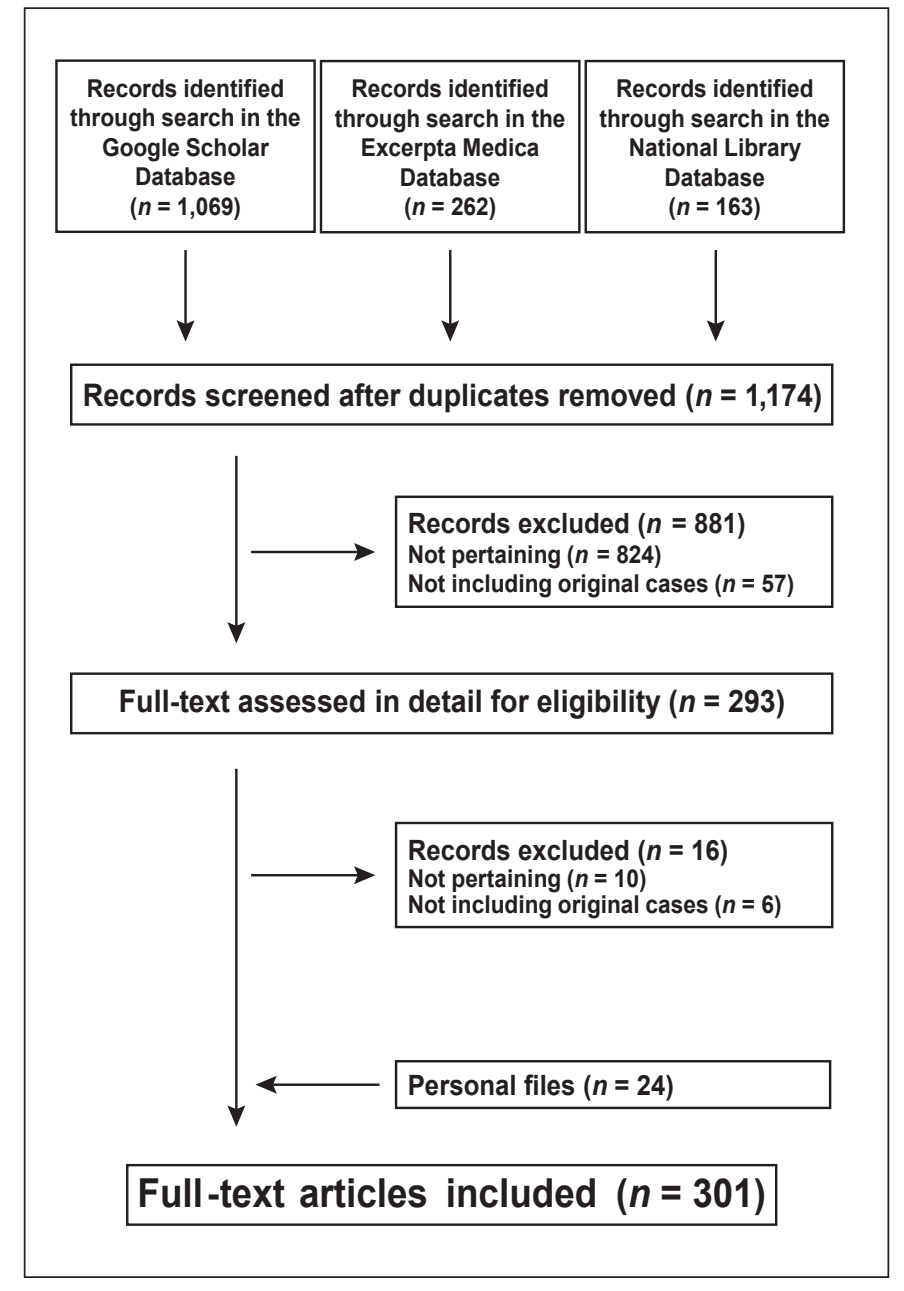

Fig. 2. Skin eruptions in acute hemorrhagic edema of young children. The Preferred Reporting Items for Systematic Reviews and MetaAnalyses, a recognized set of items for reporting, were followed.

mented evolution of eruptions did not significantly differ with respect to sex and age.

In the mentioned 81 cases, a papular wheal, a macule, or a simple wheal often preceded the classic nummular or annular eruption (Fig. 3). A nummular eruption often evolved into an annular targetoid or, less frequently, into an annular nontargetoid eruption. Finally, both the evolution of an annular nontargetoid into an annular targetoid eruption and, less frequently, the opposite were also reported.

\section{Discussion}

Acute hemorrhagic edema of young children is typically confined to the skin. Textbooks and reviews state that extensive edema and round (either nummular or an- 
Table 1. Acute hemorrhagic edema of young children: glossary of skin eruptions utilized for the present analysis of the literature

\section{Annular eruption}

Annular eruption in a strict sense: raised, ring-shaped (circular or ovoid) eruption with well-defined border, $\geq 10 \mathrm{~mm}$ in maximal diameter that lasts $\geq 24 \mathrm{~h}$

Targetoid annular eruption: with 3 zones of color

Nontargetoid annular eruption: with only 2 zones of color (often referred to as atypical targets)

Polycyclic eruption: raised coalescing annular (or arciform) eruption*

Arciform eruption: raised arc-shaped eruption (considered an incompletely formed annular eruption)*

Nummular eruption

Raised coin-shaped eruption with well-defined border, $\geq 10 \mathrm{~mm}$ in maximal diameter that lasts $\geq 24 \mathrm{~h}$

Edema

Swelling produced by expansion of the skin fluid volume

Further eruptions

Petechia: nonblanching spot eruption $\leq 3 \mathrm{~mm}$ in diameter

Purpuric eruption: nonblanching, typically raised eruption, 4-10 $\mathrm{mm}$ in diameter

Ecchymosis: nonblanching, typically raised eruption, $>10 \mathrm{~mm}$ in diameter (with a nonround shape)

Macule: blanching flat area of discoloration, usually $\leq 10 \mathrm{~mm}$ in diameter

Simple wheal: elevated eruption, usually ovoid or circular and $\geq 10 \mathrm{~mm}$ in diameter lasting $<24 \mathrm{~h}$ (usually pruritic)

Papular wheal: elevated eruption $\leq 10 \mathrm{~mm}$ in diameter resembling an insect bite (but without a central "focus")

Scratch mark: narrow elongate loss of skin (= excoriation)

* Either targetoid or nontargetoid.

nular) eruptions characterize this condition [1-4]. This careful review points out that the symmetrically distributed rash of this vasculitis is more heterogeneous than so far believed and may be summarized and discussed as follows.

Tenderness (or pain), induration, and absent indentation after pressure characterize skin edema in most children with hemorrhagic edema. In our experience, warmth is a further feature. Terms such as acute inflammatory skin edema or, more rarely, noninfectious pseudo-cellulitis have been used to denote this rare but peculiar form of skin edema [10].

The vast majority of children present with both nummular and annular eruptions. In addition to annular eruptions in a strict sense, many children present with polycyclic or arciform eruptions. On the other hand, annular eruptions in a broad sense may be either nontargetoid (i.e., with only two zones of color) or targetoid (i.e., with three zones of color).

Purpuric eruptions and ecchymoses are reported in the majority of cases (sometimes in association with petechiae). Macules and both simple and papular wheals may also occur. Scratch marks, specific signs associated with pruritus, are uncommon.

The initial eruption may be either a simple or papular wheal or a macule that evolves into a nummular or, less frequently, directly an annular eruption. Nummular eruptions successively evolve into annular ones. Finally, both the evolution of an annular nontargetoid into a clas-
Table 2. Skin eruptions reported in 383 patients ( 261 males and 122 female) affected by acute hemorrhagic edema of young children

\section{Annular eruptions}

Annular in a strict sense

Targetoid 314 (82)

Targetoid and nontargetoid $56(15)$

Nontargetoid $5(1.3)$

Polycyclic

Targetoid 165 (43)

Targetoid and nontargetoid $\quad 5(1.3)$

Nontargetoid 4 (1.0)

Arciform

Targetoid 91 (24)

Targetoid and nontargetoid 8 (2.1)

Nontargetoid $6(1.6)$

Total $375(98)$

\begin{tabular}{ll}
\hline Nummular eruptions & $358(93)$ \\
\hline Edema & $383(100)$ \\
\hline Further eruptions* & $\mathbf{3 8 3 ( 1 0 0 )}$ \\
\hline
\end{tabular}

Values are $n(\%)$. * Purpuric eruptions $(n=374)$, ecchymoses $(n=$ $241)$, acules $(n=50)$, simple wheals $(n=33)$, petechiae $(n=30)$, papular wheals $(n=16)$, scratch marks $(n=12)$.

sic annular targetoid eruption and, less frequently, the opposite may also occur.

Nontargetoid and especially targetoid annular eruptions are the classic hallmark of erythema multiforme [11, 12]. However, recent reports suggest that no more than one- 
Table 3. Regional distribution of annular or nummular eruptions, edema, and macules in 383 patients affected by acute hemorrhagic edema of young children

\begin{tabular}{|c|c|c|c|c|c|c|c|}
\hline & \multicolumn{4}{|c|}{ Annular eruptions } & \multirow{2}{*}{$\begin{array}{l}\text { Nummular } \\
\text { eruptions }\end{array}$} & \multirow[t]{2}{*}{ Edema } & \multirow[t]{2}{*}{ Macules } \\
\hline & Total & $\begin{array}{l}\text { Annular in a } \\
\text { strict sense }\end{array}$ & Polycyclic & Arciform & & & \\
\hline Face and ears & $288(75)$ & $285(74)$ & 71 (19) & $36(9.4)$ & $251(66)$ & $219(57)$ & $42(11)$ \\
\hline Arms and hands & $296(77)$ & $293(77)$ & $66(17)$ & $38(9.9)$ & $242(63)$ & $278(72)$ & $31(8.1)$ \\
\hline Trunk & $58(15)$ & $58(15)$ & $17(4.4)$ & $11(2.9)$ & $48(13)$ & $31(8.1)$ & $13(3.4)$ \\
\hline Genitals & $8(2.1)$ & $8(2.1)$ & $1(2.6)$ & 0 & $4(1.0)$ & $30 *(7.8)$ & $2(0.5)$ \\
\hline Legs and feet & 347 (91) & $345(90)$ & $113(30)$ & $61(16)$ & $305(80)$ & $339(89)$ & $35(9.1)$ \\
\hline
\end{tabular}

Values are $n(\%) .{ }^{*} 28$ males and 2 females $(p<0.005)$

Fig. 3. Evolution of round skin eruptions in 81 patients affected by acute hemorrhagic edema of young children.

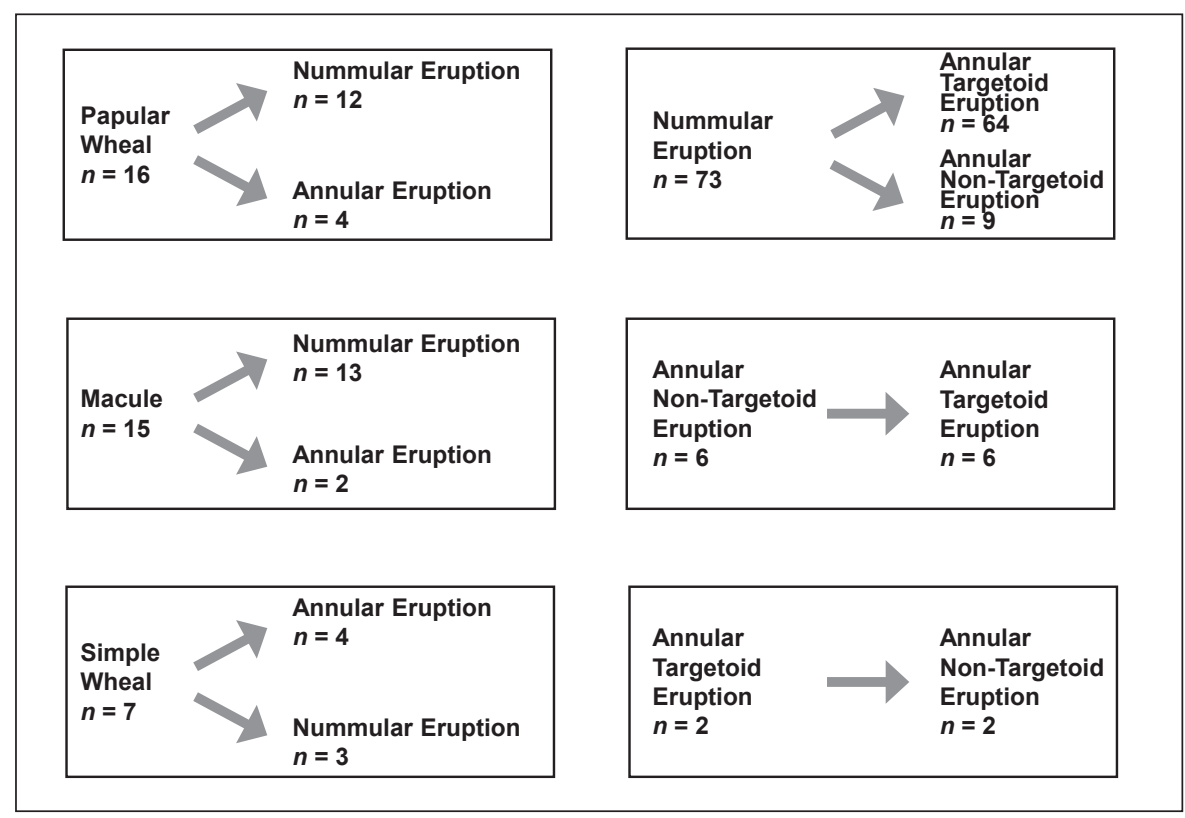

quarter of children with the mentioned skin eruption suffer from erythema multiforme $[13,14]$. In this age group, acute ordinary urticaria or urticaria multiforme and acute hemorrhagic edema underlie, in the vast majority of cases, targetoid-like eruptions [13-15]. Since erythema multiforme is rare before the age of 4 years, hemorrhagic edema accounts for targetoid-like eruptions in many children 3 years or less of age. The inappropriate term "infantile erythema multiforme" has been sometimes utilized in the past to denote hemorrhagic edema of young children [14]. Syphilis and paintball injuries are further rare causes of targetoid or nontargetoid annular eruptions in childhood [13-15].

Dispute exists as to whether immunoglobulin A vasculitis and acute hemorrhagic edema of young children are different clinical features of the same disease or separate diseases. Some believe that hemorrhagic edema is the infantile variant of immunoglobulin A vasculitis. This statement is sustained by a report documenting the concomitant appearance of hemorrhagic edema and immunoglobulin A vasculitis in first-degree relatives [16]. Cases also exist of children with findings overlapping between the two vasculitides [17]. On the other hand, there are sufficient data to consider hemorrhagic edema a distinct entity, including the failure to detect depositions of immunoglobulin $\mathrm{A}$ in most biopsy specimens and the skin-limited involvement. The present systematic analysis, which documents type and distribution of skin eruptions in hemorrhagic edema, further supports this assumption. A report recently released by some of us identified a truncating variant in the HCK gene in 4 subjects affected by hemorrhagic edema [18]. This gene 
is located on chromosome 20 and encodes for a proteintyrosine kinase that is predominantly expressed in hemopoietic cells. Furthermore, aberrant activity of the HCK gene has been noted in inflammatory and cancer diseases. Further investigations are warranted to determine if and how the HCK gene is involved not only in hemorrhagic edema but also in immunoglobulin A vasculitis.

Skin vasculitides, including, among others, immunoglobulin A vasculitis, have been associated with the severe acute respiratory syndrome coronavirus 2 [19]. To the best of our knowledge, no cases of hemorrhagic edema have been so far reported in patients affected by this virus. In 2017, acute hemorrhagic edema was observed in an infant with an upper respiratory infection caused by coronavirus NL63 [20].

The most important limitation of the present analysis comes from the small number of published articles on children affected by hemorrhagic edema, which were published over 50 years. A second limitation is that the analysis incorporated exclusively data from case reports. Finally, because the diagnosis of hemorrhagic edema is mostly made on clinical grounds, diagnostic accuracy depends on experience and skills of the examiner.

\section{Conclusion}

This is the first study which carefully characterizes type, distribution, and evolution of skin eruptions in hemorrhagic edema of young children. These data help physicians to rapidly and noninvasively make the clinical diagnosis of this apparently alarming but very benign vasculitis.

\section{Key Message}

This study carefully characterizes type, distribution, and evolution of eruptions in acute hemorrhagic edema.

\section{Statement of Ethics}

Verbal informed consent to publish the pictures was obtained from the parents of the children prior to the publication. This consent procedure was reviewed and approved by the Ethics Committee of Southern Switzerland (approval number 3653).

\section{Conflict of Interest Statement}

The authors have no conflicts of interest to declare.

\section{Funding Sources}

This research received no external funding.

\section{Author Contributions}

P.O.R., M.G.B., S.A.G.L., and G.P.M. developed the Acute Hemorrhagic Edema Bibliographic Database; G.B., P.O.R., M.G.B., and G.P.M. conceptualized the study design; G.B. and P.O.R. extracted the data; G.B., C.L., and S.A.G.L. analyzed the data; G.B., M.G.B., and G.P.M. wrote the manuscript; all authors read and commented on the final version of the manuscript.

\section{References}

1 Smitt JH, Vermeer MH, Faber WR. Acute hemorrhagic edema of infancy (AHEI). Clin Dermatol. 2002;20(1):2-3.

2 Fiore E, Rizzi M, Ragazzi M, Vanoni F, Bernasconi M, Bianchetti MG, et al. Acute hemorrhagic edema of young children (cockade purpura and edema): a case series and systematic review. J Am Acad Dermatol. 2008;59(4): 684-95.

3 Ting TV. Diagnosis and management of cutaneous vasculitis in children. Pediatr Clin North Am. 2014;61(2):321-46.

4 Lava SAG, Milani GP, Fossali EF, Simonetti GD, Agostoni C, Bianchetti MG. Cutaneous manifestations of small-vessel leukocytoclastic vasculitides in childhood. Clin Rev Allergy Immunol. 2017;53(3):439-51.

5 Rinoldi PO, Bronz G, Ferrarini A, Mangas C, Bianchetti MG, Chelleri C, et al. Acute hem- orrhagic edema: uncommon features. J Am Acad Dermatol. 2020;S0190-9622(20)332242.

6 Pellanda G, Lava SAG, Milani GP, Bianchetti MG, Ferrarini A, Vanoni F. Immune deposits in skin vessels of patients with acute hemorrhagic edema of young children: A systematic literature review. Pediatr Dermatol. 2020; 37(1):120-3.

7 Rinoldi PO, Milani GP, Bianchetti MG, Ferrarini A, Ramelli GP, Lava SAG. Acute hemorrhagic edema of young children: open questions and perspectives. Int J Dermatol Skin Care. 2019;1:63-7.

8 Nast A, Griffiths CE, Hay R, Sterry W, Bolognia JL. The 2016 International League of Dermatological Societies' revised glossary for the description of cutaneous lesions. Br J Dermatol. 2016;174(6):1351-8.
9 Brown GW, Hayden GF. Nonparametric methods. Clinical applications. Clin Pediatr (Phila). 1985;24(9):490-8.

10 Marchionne EM, McCalmont TH, Pincus LB, LeBoit PE, Fox LP. Acute inflammatory edema: A mimicker of cellulitis in critically ill patients. J Am Acad Dermatol. 2019;81(4):9316.

11 Hughey LC. Approach to the hospitalized patient with targetoid lesions. Dermatol Ther. 2011;24(2):196-206.

12 Wolf R, Lipozencic J. Shape and configuration of skin lesions: targetoid lesions. Clin Dermatol. 2011;29(5):504-8.

13 Siedner-Weintraub Y, Gross I, David A, Reif S, Molho-Pessach V. Paediatric erythema multiforme: epidemiological, clinical and laboratory characteristics. Acta Derm Venereol. 2017;97(4):489-92. 
14 Milani GP, Lava SAG, Bianchetti MG. Differential diagnosis of erythema multiforme in childhood: A Comment to Siedner-Weintraub et al. Acta Derm Venereol. 2018;98(1): 169.

15 Mathur AN, Mathes EF. Urticaria mimickers in children. Dermatol Ther. 2013;26(6):46775.
16 Gattorno M, Picco P, Vignola S, Di Rocco M, Buoncompagni A. Brother and sister with different vasculitides. Lancet. 1999;353(9154):728.

17 Nussinovitch M, Prais D, Finkelstein Y, Varsano I. Cutaneous manifestations of HenochSchönlein purpura in young children. Pediatr Dermatol. 1998;15(6):426-8.

18 Bronz G, Gabriel H, Antonio Lava S, Paolo Ramelli G, Luedeke M, Biskup S, et al. Whole exome sequencing revealed a candidate gene for Finkelstein-Seidlmayer disease. Am J Pediatr. 2019;5(4):196-9.
19 Genovese G, Moltrasio C, Berti E, Marzano AV. Skin manifestations associated with COVID-19: Current knowledge and future perspectives. Dermatology. 2021;237(1):1-12.

20 Chesser H, Chambliss JM, Zwemer E. Acute hemorrhagic edema of infancy after coronavirus infection with recurrent rash. Case Rep Pediatr. 2017;2017:5637503. 